\title{
$O$ uso intensivo da internet por crianças e adolescentes no contexto da COVID-19 e os riscos para violências autoinflingidas
}

\author{
The intensive use of the internet by children and adolescents in the \\ context of COVID-19 and the risks for self-inflicted violence
}

Suely Ferreira Deslandes (https://orcid.org/0000-0002-7062-3604) ${ }^{1}$

Tiago Coutinho (https://orcid.org/0000-0002-0545-9457) ${ }^{2}$

${ }^{1}$ Instituto Fernandes Figueira, Fiocruz. Av. Rui Barbosa 716, Flamengo. 22250-020 Rio de Janeiro RJ Brasil.

deslandes.s@gmail.com ${ }^{2}$ Núcleo de Atendimento Farmacêutico, Escola Nacional de Saúde Pública, Fiocruz. Rio de Janeiro RJ Brasil.

\begin{abstract}
This essay aimed to discuss the implications of social isolation due to the COVID-19 pandemic for the intensive use of the internet among children and adolescents and its possible consequences for the practice of self-inflicted violence. We briefly discussed the anxiogenic potential and the reproduction of a "global fear" that are consolidated with the massive and unmediated exposure of the content consumed, which can increase the vulnerabilities to stress and suicidal ideas. We centered our debate on "recreational" practices, called "challenges" with self-harm power, carried out by teenagers on the YouTube website. This practice has been shown to increase with the social isolation measures. Our reflection on these risks builds on the theoretical perspective of digital sociability, and its implications for the internet-mediated interactions of adolescents.
\end{abstract}

Key words Self-inflicted violence, Internet, COVID-19, Social isolation, Online challenges
Resumo O presente ensaio busca discutir as implicações do isolamento social devido à pandemia do COVID-19 para o uso intensivo da internet entre crianças e adolescentes e suas possiveis consequências para a prática de violências autoinflingidas. Discutimos brevemente o potencial ansiogênico e a reprodução de um "medo global" que se consolidam com a exposição maciça e sem mediação dos conteúdos consumidos, que podem aumentar as vulnerabilidades para estresse $e$ ideações suicidas. Centramos nosso debate sobre práticas "recreativas", denominadas de "desafios" com poder autolesivo, realizados por adolescentes no site Youtube. Essa prática revelou-se crescente a partir das medidas de isolamento social. Nossa reflexão sobre esses riscos é feita a partir da perspectiva teórica da sociabilidade digital, e suas implicações nas interações de adolescentes mediadas pela internet.

Palavras-chave Violência autoinflingida, Internet, COVID-19, Isolamento social, Desafios online 


\section{Pandemia e o Isolamento Social}

No dia 11 de março de 2019, a Organização Mundial de Saude $(\mathrm{OMS})^{1}$ declarou que o novo corona vírus (Sars-cov-2), causador da doença Covid-19, passou do estágio de uma epidemia para o de uma pandemia. Esta decisão foi tomada tendo em vista o aumento exponencial do número de casos ao redor do mundo. Desta forma, a OMS sugeriu que todos os países adotassem o protocolo do isolamento social como a principal medida a ser tomada para conter a expansão da pandemia.

Sabe-se que tal medida não foi adotada por todos os países igualmente, nem por todos os grupos e classes sociais. No Brasil, verifica-se uma profunda desigualdade entre os que tinham os recursos sociais, financeiros e valores sanitários que favorecem a adoção dessa forma de proteção. Todavia, inegavelmente, milhões de pessoas no mundo inteiro se viram obrigadas a interromper bruscamente boa parte das interações humanas face a face (presenciais). De uma hora para a outra a transmissão de dados por meio digital, genericamente chamada de Internet, tornou-se o único meio disponível para a não interrupção completa das interações sociais e de trabalho, na tentativa de simular e restabelecer uma nova forma de normalidade frente à pandemia. Se antes do protocolo de isolamento social já se discutia com exaustão a questão da fluidez da fronteira entre as sociabilidades online $\mathrm{x}$ off-line $\mathrm{e}^{2,3}$, pela primeira vez o contato com o mundo off-line só está sendo possível para essas pessoas em situação de isolamento pela via da conexão digital.

Partindo de reflexões estimuladas por resultados de pesquisa que tiveram como objetivo analisar a relação entre as redes sociais digitais e as violências vividas e praticadas na ambiência digital por crianças e adolescentes, este ensaio parte do princípio de que o isolamento social adotado para o enfrentamento da Pandemia do Covid-19 intensificou alguns elementos ligados à sociabilidade digital (hiperexposição, diluição de fronteiras público-privadas-íntimas, espetacularização de si) $)^{4-8}$ que criam condições para o acirramento da violência digital.

O período do isolamento social provocado por esta pandemia coincidiu com o momento de consolidação, popularização e expansão, ainda que desigual, para todas as classes sociais da chamada Internet 2.0. A web 2.0 possui como principais características a hiperinteratividade entre os usuários e a mobilidade em que podem ser acessados estes espaços digitais.
Impulsionada pela quantidade massiva de dados trocados na Internet banda larga, a hiperconectividade acontece através de diversas ferramentas como troca de mensagens de texto, fotos, áudios, transmissão ao vivo, sala de reuniões; em suma, mecanismos que potencializam a interação entre as pessoas. A nanotecnologia associada ao amplo acesso da área de cobertura da Internet fez com que estes espaços de interação pudessem ser acessados em qualquer lugar a qualquer hora sem a necessidade de um mediador.

A hiperconectividade e a mobilidade da Internet 2.0 trouxeram aquilo que autores apontam como sendo a principal característica da sociabilidade digital, a espetacularização do "eu" na busca de um reconhecimento midiático da sua perso$\mathrm{na}^{9-11}$. A partir de plataformas como Instagram, Twitter, Facebook, Tinder, etc. observa-se que a sociabilidade mediada pelo mundo digital depende da forma que o "eu" irá se apresentar para os "outros", os quais se presentificam de diversas maneiras no discurso construído por este "eu" digital. Na pretensão de ser amado, apreciado e aplaudido, os indivíduos estariam submetidos ao que Sibilia" chamou de "tiranias da visibilidade", tendo que estilizar e cultivar suas imagens aos moldes de personagens da mídia audiovisual e "atuar como se estivesse sempre diante de uma câmera, disposto a se exibir em qualquer tela". A autora afirma que vivemos tempos em que as personalidades são convocadas e a visibilidade se constitui em uma nova forma de existir nas sociedades ocidentais'. A hiperexposição torna-se assim uma característica intrínseca desta sociabilidade digital. Tais elementos são agudizados nas mediações digitais das interações entre os mais jovens, para quem a autoestima é afirmada a partir da aceitação nas mídias sociais, pelo olhar e aprovação do outro (conhecidos e desconhecidos) 5 .

Esta construção da imagem de si mediada por ferramentas tecnológicas tem como consequência a potencialização de um fenômeno característico da modernidade e do surgimento dos grandes centros urbanos de colocar a intimidade como principal foco de espetacularização ${ }^{12,13}$. De acordo com Sibilia": "A constante reafirmação do eu em suas complexas relações com o outro, a narrativa, a privacidade, a visibilidade, a instantaneidade, o culto à personalidade, a ficção, a solidão e o espetáculo, permite entender a transformação da intimidade em espetáculo como uma complexa relação entre o eu, os outros e nós no interior da cibercultura".

Nesta sociabilidade digital impulsionada por uma espetacularização do eu que tem na intimi- 
dade seu principal foco de exposição, observa-se como principal consequência um barramento entre as fronteiras que separam a esfera do público e do privado. Atualmente, usuários, bilionários donos de plataformas, advogados, políticos e sociedade civil discutem as novas fronteiras destas instâncias através de casos polêmicos como trocas de imagens intimas, documentos pessoais ou captura de dados ligados à saúde. Ainda não está claro para o usuário da Internet 2.0 se uma publicação, um comentário ou um compartilhamento de material audiovisual pertenceàs esferas ligadas ao público ou ao privado.

Em contrapartida, neste contexto de exceção das interações cotidianas, como se vivencia com o isolamento social na pandemia de Covid-19, a Internet torna possível que alguma forma de normalidade seja reestabelecida simulando aspectos que anteriormente eram restritos ao mundo offline. Além do trabalho realizado em casa, observase que a rotina das pessoas passou a ser mediada exclusivamente pelo mundo digital, tentando imprimir uma agenda de atividades capazes de ocupar de "forma saudável" o tempo de isolamento: pilates, yoga, musculação, podcast, reuniões, festas, apresentação online, jogos de azar em rede, disputa de videgames, etc.

Assim, se espera que a circulação e a interação nos ambientes digitais no contexto da pandemia possa evitar os diversos efeitos colaterais que o isolamento pode ocasionar como depressão, ansiedade, solidão, maior vulnerabilidade às violências familiares e entre parceiros, possíveis tentativas de suicídios ligados à falta da sociabilidade presencial e ao clima social de medo em relação aos desdobramentos da pandemia. Aposta-se que a interatividade e a mobilidade da Internet podem amenizar os efeitos desta medida que suprimiu para tantos a presencialidade da interação humana. A maioria das agências transnacionais de saúde e proteção à infância sugere ainda que o contato social seja mantido pelas vias digitais como forma de prevenção e busca de apoio para as situações que envolvem as principais violências da esfera familiar e de intimidade amorosa, bem como das violências autoinflingidas ${ }^{14,15}$. Mas como ficaria a vulnerabilidade desses adolescentes a violências justamente pelo contato mais prolongado com as redes sociais na ambiência digital?

O presente ensaio busca, portanto, discutir as implicações do isolamento social devido à pandemia do Covid-19 para o uso intensivo da internet entre crianças e adolescentes e suas possíveis consequências para a prática de violências autoinflingidas. Segundo a definição da OMS ${ }^{16}$, a violência autoprovocada/autoinfligida compreende um largo espectro de fenômenos, desde a ideação suicida, as autoagressões, a tentativas de suicídio e os suicídios.

\section{Uso intensivo da internet e a vulnerabilidade para tentativas e práticas autolesivas}

O primeiro aspecto a se discutir diz respeito aos conteúdos (informações, memes, depoimentos etc.) que falam da situação da pandemia, seus prognósticos e o seu grande potencial ansiogênico, potencializando um "medo global" ("temor totalizante sentido por todos os habitantes de um coletivo, na expectativa de uma enorme quantidade de mortes que potencialmente ou de fato atingirá a todos e acabará o mundo conforme foi conhecido até um determinado momento") ${ }^{17}$.

A pandemia do coronavírus é a primeira que se vive no tempo on-line. A internet, com sua multiplicação da capacidade de comunicação capilar, ao mesmo tempo em que propicia uma tomada de consciência global cria uma expectativa e uma paranoia na espera de que os grandes números de doentes e mortos, supostamente definidos de forma milimétrica diariamente, não atinjam com a mesma intensidade os locais em que vivemos ${ }^{17}$.

De acordo com o relatório de orientação sobre o manejo familiar no contexto do Covid-19 do UNICEF, sem a ajuda parental para atribuir significados para a pandemia, as crianças ou os adolescentes podem aumentar sua carga de estresse e ansiedade ${ }^{18}$. Assim, agências internacionais tais como UNICEF, Organização Mundial de Saúde, Internet of Good Things, End Violence Against Children e Usaid sugerem que as informações sobre a pandemia sejam mediadas pelos pais, sem segredos, mas com linguagem compreensível para as diferentes idades e fases de desenvolvimento, permitindo que crianças e adolescentes possam expressar seus sentimentos, angústias e dúvidas e assim elaborar psíquica e culturalmente a situação, sem preconceitos ou xenofobias $^{14,15,18}$. Naturalmente, essa orientação vem revestida da idealização de que pais e outros adultos tenham o discernimento e comportamentos de temperança, numa lógica racionalizadora, o que não leva inteiramente em conta os processos de interpretação cultural, apropriados de forma diferente por cada grupo social.

Como alertam as mesmas agências de proteção à infância, o consumo massivo de conteúdos 
sobre a situação da epidemia (número de casos, número de mortos) pode gerar ansiedade, pânico bem como pode levar à depressão. Tais questões podem ser muito mais intensas quando a criança ou o adolescente já apresentem condições de saúde mental prévias e que demandem monitoramento, portanto constituindo o acirramento de vulnerabilidades para ideações e tentativas de suicídios.

O próprio uso excessivo da internet, pode também gerar uma forma de adição ${ }^{19}$, um transtorno que gera dependência, expressando-se nas cinco formas catalogadas pelo Center for Online Addiction: 1- o cyber sexo (cybersex), 2- a relacional (das redes sociais), 3- o Net Gaming Addiction, que inclui uma ampla gama de comportamentos, como jogos de azar, videogames, compras e comércio eletrônico obsessivo 4- a busca de informações; 5- a adição por jogos. Se os mais jovens já eram os internautas com maior tempo de $\mathrm{uso}^{20}$, com a medida de isolamento social essa condição de exposição parece se acirrar. Mais uma vez, os limites entre as definições nosológicas de transtorno e normalidade serão redefinidas e interpretadas pelo grau de tolerância cultural a tais práticas.

Inferimos, portanto, que no contexto dessa sociabilidade digital em situação excepcional de isolamento social, com uso intensivo da internet, pode aumentar a vulnerabilidade de crianças e adolescentes às violências autoinflingidas.

Trataremos a seguir das autoagressões, que não necessariamente envolvem transtornos de ordem emocional ou quadros depressivos, mas são vistos como práticas culturais aceitas socialmente como "jogos e brincadeiras" no universo online.

\section{A internet, o uso do tempo e a administração da imagem de si}

Os guias que tratam do tema do uso do tempo entre adolescentes na fase de isolamento social devido à pandemia sugerem a criação de rotinas de atividades de estudos, lazer e exercícios ${ }^{15,21}$. Se é certo que tais sugestões levam em conta uma rotina saudável, há igualmente uma dose de idealização das condições de sua realização, que a depender do espaço que se dispõe, número de filhos e demais habitantes da casa tornam tais conselhos difíceis de serem seguidos. O Unicef em seu guia "How teenagers can protect their mental health during coronavirus (COVID-19)"21 que sugere dicas de manejo das condições de estresse e sobre o uso do tempo, destacando as sugestões de criar distrações e de manter o contato online com a rede de amigos. Na dica "seja gentil consigo e com os outros" menciona a possibilidade de o adolescente sofrer cybulling e recomenda que caso isso ocorra procurem a ajuda de adultos.

Adolescentes, mesmo em quarentena, mantêm seus laços de sociabilidade digital e se veem, como antes, convocados a manter sua visibilidade no universo online. A sua imagem precisa circular nos circuitos de suas relações e para alguns reafirma-se a expectativa já reconhecidamente estimulada nessa ambiência cultural de se "tornar famoso" e, quiçá, se tornar um "digital influencer"22. A busca de fama nos meios digitais reorganiza as consciências para a constante exibição e o acompanhamento de relatos minuciosos da vida. Toda a vida torna-se passível de ser midiatizada. A personalidade do autor, suas peripécias, rotinas e opiniões ganham suportes imagéticos, sonoros, textuais, audiovisuais ou todos interligados ao mesmo tempo, na função de mostrar "a vida como ela é" ${ }^{23}$. Essas técnicas de midiatização do cotidiano se intensificam entre as webcelebridades, que costumeiramente transformam suas rotinas em reality shows que podem ser acompanhados através do mundo digital.

Uma das principais plataformas que hospeda o material audiovisual destas webcelebridades é o Youtube. Em seu livro "Youtube e a revolução digital" 24 acrescentam que o sucesso do site pode ter sido ocasionado também por uma mudança de foco nos ideais da empresa. Esta mudança foi observada na troca de seu principal slogan. Nos primeiros anos de existência o site trazia o slogan "Your Digital Video Repository" ("Seu Repositório de Vídeos Digitais"), atualmente encontra-se o "Broadcast yourself" ("Transmita-se") expressando os novos anseios e ideias da empresa. Essa mudança de conceito fez que o site se transformasse de um recurso de armazenagem pessoal de conteúdos em vídeo para uma plataforma destinada à expressão pessoal colocando o YouTube no contexto das noções de uma revolução liderada por usuários que caracteriza a retórica em torno da "Web 2.0". Nesta nova fase, o YouTube atrai a atenção para o conteúdo ao mesmo tempo em que oferece uma participação em dinheiro nas vendas de anúncios no site.

Assim, os youtubers se tornaram uma importante fonte de informação e entretenimento para a geração "nativa digital" 25 . Os youtubers influentes são frequentemente descritos como microcelebridades. Sendo concebido como uma plataforma de vídeo de mídia social de baixo para 
cima o YouTube transmite a sensação de que as microcelebridades não estão envolvidas com o sistema estabelecido e comercial da cultura de celebridades, apresentando-se para seu público como autogovernados e independentes. Essa aparência, por sua vez, faz com que os usuários do YouTube sejam vistos como mais compreensíveis e autênticos, também estimulados pela conexão direta com o espectador usando os meios de interatividade disponibilizados pelo YouTube (comentários, mensagens e links).

Um dos principais conteúdos disponibilizados no YouTube que retratam esta espetacularização de si são os desafios online que envolvam algum tipo de autolesão. A peculiaridade desses atos é que são revestidos do tom de "brincadeira" ou assumem o formato de um "game", sem que seus participantes tenham necessariamente noção dos danos que podem sofrer ao realizar as tarefas prescritas.

O desafio mais famoso foi conhecido sob o game da "Baleia Azul", cuja criação se atribui ao russo Fillipp Budeykin, que supostamente aliciava jovens para grupos de suicídio. O jogo envolvia uma série de tarefas diárias que eram enviadas com antecedência ou de forma instantânea e desafiavam inclusive à automutilação, culminando com a tarefa de suicidar-se ${ }^{26}$. São diversos os "desafios" lançados, muitas das vezes por youtubers mirins ou por adolescentes que convidam seu público a ingerir água fervendo, inalar desodorante e prender a respiração, entrar em apneia por tempo indeterminado, se autoenforcar, tirar autorretratos (selfie) em situações de risco, engolir substâncias, se autolesionar e até mesmo se matar. Tais "desafios", vistos como piada e evento a ser filmado e postado, ganham popularidade em vários países.

A partir de uma pesquisa realizada no Google Trends foi possível observar que a busca pelo termo "desafios online" (challenges online) cresceu bastante no mundo inteiro após a medida de isolamento social ter sido implementada. Seguindo o histórico de recorrências desta palavra-chave no motor de busca do Google, foi possível constatar que a partir de 8 de março de 2020 aconteceu a maior ascensão da reta que representa o número de buscas por este termo nos últimos 12 meses. É interessante notar que o pico deste gráfico acontece no dia 12 abril quando se atingiu o maior número de buscas neste período de tempo (Figura 1).

Tomaremos como caso para ilustrar esse debate um dos desafios que tem se disseminado no Brasil em tempos de pandemia e medo de con- taminação com o novo Covid-19: o desafio do álcool em gel - um dos produtos mais requisitados para higienização e prevenção ao contágio. De acordo com especialistas, o álcool a 70\% seria eficaz na eliminação do vírus. Junto com as máscaras, o produto tornou-se símbolo de combate à pandemia provocando desabastecimento em vários estados do Brasil. Aproveitando a popularidade do produto e a alta exposição na mídia, diversos youtubers propuseram ao seu público o desafio do Álcool em Gel.

Dentre os 10 vídeos brasileiros mais acessados a partir da busca feita com a palavra-chave "Desafio álcool em Gel", os desafios mais populares com o produto tratam das seguintes práticas: inalar, beber e atear fogo em uma quantidade do produto no corpo do desafiante ou cuspir o produto em direção a uma chama. $\mathrm{O}$ vídeo com mais acesso deste pequeno acervo possui $421 \mathrm{mil}$ visualizações em apenas uma semana e 18.023 o que possui menos. Nos vídeos de inalação, os desafios consistem em colocar uma pequena quantidade de álcool em gel em uma superfície em forma de linha reta e com um canudo ou qualquer outro objeto cilíndrico inspirar o álcool gel para a narina do desafiante causando reações como ardência, espirros, vômitos, náuseas e necessidade de beber agua. Nos desafios de ingestão, o desafiante propõe para seu público que o álcool em gel seja bebido diretamente de seu frasco, como se fosse uma dose de uma bebida destilada.

Assim como os desafios de inalação, diversas crianças e adolescentes dão depoimentos acerca dos efeitos colaterais vividos. O último tipo de desafio realizado com o álcool em gel foi o que ganhou maior notoriedade e repercussão obrigando o Youtube a retirá-lo de sua plataforma por violar as regras de segurança estabelecidas pela empresa. Em busca recente não foi mais possível ver esse desafio em si, restando apenas reportagens e comentários de outros youtubers sobre os perigos envolvidos. Trata-se do desafio de colocar o álcool em gel na boca, para em seguida cuspir esta fração do produto em direção ao fogo de um isqueiro ou uma vela. Envolvendo ainda o risco das queimaduras, ainda há a possibilidade de passar o produto nas mãos ou braços e atear fogo. Outro desafio realizado com álcool em gel, porém que não oferece risco aos participantes foi o desafio idealizado por Falcão, jogador da seleção brasileira de futebol de salão, que consiste em fazer o maior número de "embaixadinhas" com o frasco do produto ou passando-o nas mãos.

O desafio do álcool em gel é certamente efêmero, porque a cada novo tema ou situação que 


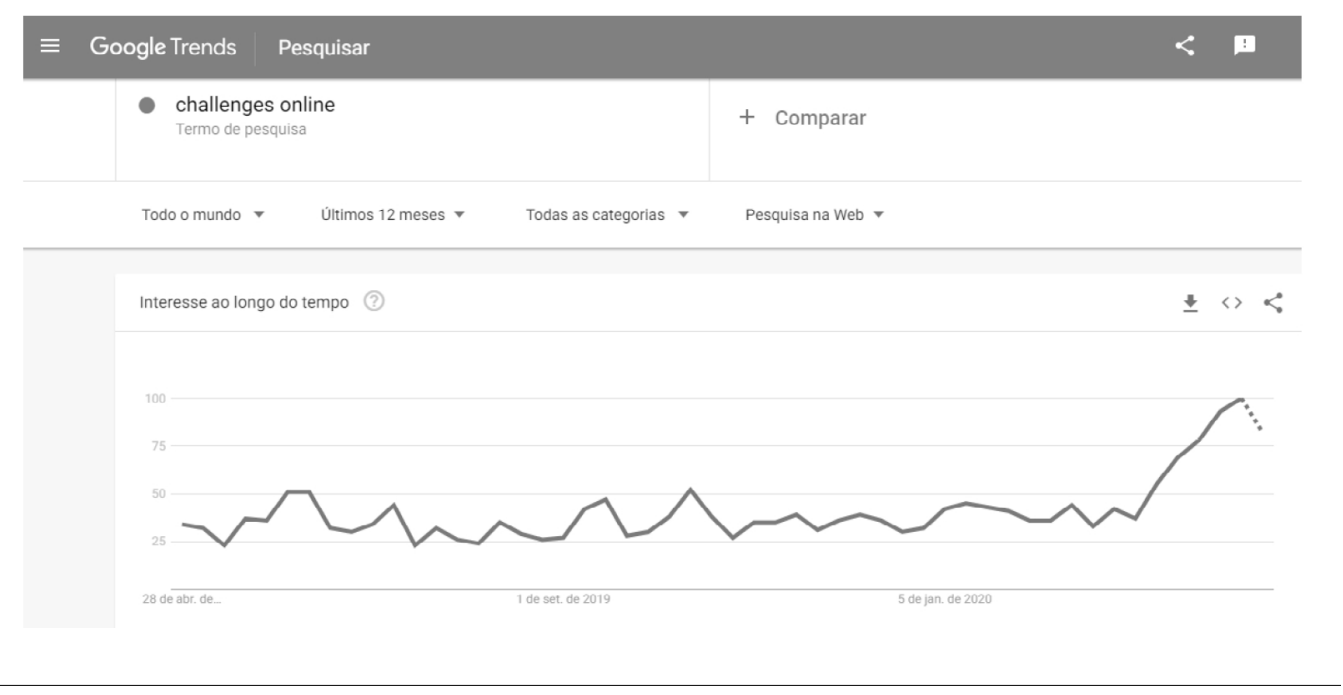

Figura 1. Distribuição de buscas online para Desafios Online, abril 2019-abril 2020.

Fonte: Google Trends. https://trends.google.com.br/trends/. Consulta em 23/04/2020.

atraia a atenção da mídia e com isso se vislumbre a possibilidade de ganhar visibilidade, novos desafios surgirão. Os desafios do "desmaio", do enforcamento, da ingestão de bebidas alcóolicas, da água quente etc. se revezaram nas plataformas, sendo substituídos semanalmente por outros mais espetaculares.

Os desafios não são práticas infantojuvenis novas. Diversas gerações brincaram de desafiar ou cumprir atividades que envolvessem algum risco diante de um grupo de pares, demonstrando coragem e protagonismo ${ }^{27,28}$. Todavia, na internet, os desafios têm um papel ampliado por uma cultura digital, sem a mediação presencial dos amigos ou adultos. Nem todos os desafios envolvem danos, podem ter o caráter de "superação", de desempenho atlético ou de habilidades, mas podem também envolver riscos com grande potencial lesivo à saúde e à integridade física. E exatamente os desafios com tais riscos são os que ganham maior notoriedade, passando a funcionar como uma estratégia, com roupagem de "brincadeira", que tem o potencial de permitir destaque nas mídias de disseminação digital, quiçá ficar "famoso" em seus grupos.

\section{Considerações finais}

O guia da OMS "COVID-19 parenting"15 reconhece que o uso da internet para os adolescentes é essencial a sua sociabilidade, mas sugere que os conteúdos sejam de conhecimento e até mesmo de monitoramento pelos pais. Esse é um tema controverso, pois diz respeito à autonomia e à privacidade dos mais jovens, por um lado, e por outro o controle parental ${ }^{29,30}$.

$\mathrm{O}$ desafio ainda envolve um monitoramento que não se dá pela via técnica (criar barreiras de acesso a certos conteúdos, por exemplos), pois os pais em geral têm menor domínio digital em relação aos adolescentes e até crianças. Instituições que trabalham com a prevenção de práticas violentas e lesivas na internet, tais como a SaferNet, Instituto Dimicuida, Inhope, entre outras, apostam na perspectiva da educação digital.

Se os adolescentes são habilidosos com tecnologias, em contrapartida são imaturos para discernir acerca dos riscos envolvidos em certas práticas correntes na sociabilidade digital, bem como as chaves de interpretação e mediação dos conteúdos e informações que são consumidas quase que sem "filtros".

O diálogo e a escuta sem julgamento culpabilizador ainda são as ferramentas mais efetivas para saber dos filhos quais atividades fazem onli- 
ne. A oportunidade de discutir os riscos das práticas digitais lesivas está dada no contexto de uso intensivo da internet que vivemos a partir da experiência sanitária de isolamento social. Por um lado, não banalizar como “jogo” ou brincadeira tais desafios é uma forma de ajudar aos adolescentes a problematizarem os riscos envolvidos e a discutir as marcas identitárias dessa sociabilidade digital infantojuvenil. Por outro lado, o caráter lúdico, desafiador e "transgressor" como marcas da conectividade online não são deletáveis, nem devem ser "demonizados".
Por fim, os mais jovens também precisam da ajuda das gerações mais velhas para decodificarem as informações que recebem pela internet e assim significarem a pandemia, pois sem tal mediação, pode-se cair na armadilha de uma ameaça sem limites, sem agências ou protagonismos dos modos de enfrentá-la.

Acreditamos que além de criar protocolos e medidas exclusivas para os adolescentes quanto à prevenção das formas de violências autoinflingidas, através de uma linguagem clara e compatível com o seu cotidiano, faz-se necessário trazer este público para o protagonismo das ações e medidas que serão adotadas durante e após a Pandemia.

\section{Colaboradores}

SF Deslandes trabalhou na concepção e redação do texto. T Coutinho trabalhou na redação e revisão do texto. 


\section{Referências}

1. World Health Organization (WHO). Coronavirus disease 2020 (COVID-19). Situation Report-67. Geneva: WHO; 2020.

2. Horst H, Miller D, editors. Digital anthropology. London: Berg; 2012.

3. Daniels J, Gregory K, Cottom TM, editors. Digital sociologies. Bristol, Chicago: Policy Press; 2017.

4. Keen A. Hipervisibilidade. A era da grande exibição. In: Keen A. Vertigem digital: porque as redes sociais estão nos dividindo, diminuindo e desorientando. Rio de Janeiro: Zahar; 2012. p. 9-26.

5. Bruno F. Máquinas de ver, modos de ser. Porto Alegre: Editora Sulina; 2013.

6. Lemos A. As estruturas antropológicas do ciberespaço. In: Lemos A. Cibercultura: Tecnologia e Vida Social na Cultura Contemporânea. $7^{\mathrm{a}}$ ed. Porto Alegre: Editora Sulina; 2015. p. 127-162.

7. Oisakawa R. Dinâmicas relacionais contemporâneas: visibilidade, performances e interações nas redes sociais da internet. In: Primo A, organizador. Interações em rede. Porto Alegre: Editora Sulina; 2016. p. 91-109.

8. Recuero R. Ator de ameaça à face e à conversão em redes sociais na internet. In: Primo A, organizador. Interações em rede. Porto Alegre: Editora Sulina; 2016. p. 51-69.

9. Sibilia P. O show do eu: a intimidade como espetáculo. Rio de Janeiro: Nova Fronteira; 2008.

10. Abidin C. Internet celebrity Understanding Fame Online. Bingley: Emerald Publishing; 2018.

11. Santaella L. Intersubjetividade nas redes digitais. In: Primo A, organizador. Interações em rede. Porto Alegre: Editora Sulina; 2016. p. 33-47.

12. Debord G. A sociedade do espetáculo: comentários sobre a sociedade do espetáculo. Rio de Janeiro: Contraponto; 1997.

13. Giddens A. Modernidade e Identidade. Rio de Janeiro: Jorge Zahar Editor; 2002.

14. Children EVA. Protecting children during the COVID-19 outbreak: resources to reduce violence and abuse. End Violence Against Children. [acessado 2020 Abr 22]. Disponível em: https://www.end-violence. org

15. World Health Organization (WHO), UNICEF, Children EVA, Things IG, Health PfL, USAID, Center for Disease Control and Prevention, GCFL. COVID-19 parenting. [acessado 2020 Abr 22]. Disponível em: https://www.covid19parenting.com

16. Krug EG, Dahlberg LL, Mercy JA, Zwi AB, Lozano R. World report on violence and health. Geneva: World Health Organization (WHO); 2002.

17. Ribeiro GL. Medo Global. Boletim n. 5. Cientistas sociais e o coronavírus. Anpocs. [acessado 2020 Abr 22]. Disponível em: http://www.anpocs.com/index.php/ ciencias-sociais/destaques/2311-boletim-n-3
18. United Nations Children's Fund (UNICEF). How teenagers can protect their mental health during coronavirus (COVID-19). [acessado 2020 Abr 22]. Disponível em: https://www.unicef.org/coronavirus/how-teenagerscan-protect-their-mental-health-during-coronavirus-covid-19. 2020

19. Salicetia F. Internet Addiction Disorder (IAD). Procedia 2015; 191:1372-1376.

20. Agência Brasil. Brasil tem 24,3 milhões de crianças $e$ adolescentes utilizando a internet. [acessado 2020 Abr 22]. Disponível em: https://agenciabrasil.ebc. com.br/geral/noticia/2019-09/brasil-tem-243-milhoes-de-criancas-e-adolescentes-utilizando-internet

21. United Nations Children's Fund (UNICEF). How to talk to your child about coronavirus disease 2019 (COVID-19). [acessado 2020 Abr 22]. Disponível em: https://www.unicef.org/coronavirus/how-talk-yourchild-about-coronavirus-covid-19. 2020

22. Vasconcellos A. Celebridade 2.0: o Youtube e a nova fábrica de famosos [dissertação]. Vitória: UFES; 2018.

23. Vasconcellos AM, Zanetti D. (Web) celebridade: O sujeito ordinário e a narrativa cotidiana sob holofotes. Lumina 2017; 11(1):1-16.

24. Burgess J, Green J. YouTube e a revolução digital. São Paulo: Aleph; 2009.

25. Palfrey J. Nascidos na era digital: entendendo a primeira geração de nativos digitais. Porto Alegre: Artmed; 2011.

26. Silva $\mathrm{H}$, Barbosa JVA. Baleia azul: do pensamento ao ato. Psicologia 2017; 19.11.

27. Le Breton D. Le goût de la syncope: les jeux d'étranglement. Adolescence 2010; 72(2):379-391.

28. Guilheri J, Andronikof A, Yazigi L. "Brincadeira do desmaio": uma nova moda mortal entre crianças e adolescentes. Características psicofisiológicas, comportamentais e epidemiologia dos 'jogos de asfixia'. Cien Saude Colet 2017; 22(3):867-878.

29. Torres F, Vivas G. Comunicación electrónica y cyberbullying: Temas emergentes para la investigación e intervención socioeducativa. Psicología desde el caribe 2012; 29(3):707-730.

30. Ferreira TR, Deslandes SF. Cyberbulling: conceituações, dinâmicas, personagens e implicações à saúde. Cien Saude Colet 2018; 23(10):3369-3379.

Artigo apresentado em 24/04/2020

Aprovado em 26/04/2020

Versão final apresentada em 28/04/2020 
ERRATA

p. 2480

onde se lê:

No dia 11 de março de 2019,

leia-se:

No dia 11 de março de 2020, 